\title{
Diagnostic pitfall: primary myoepithelial carcinoma of the lacrimal gland, case report and literature review
}

\author{
Youssef Mahdi ${ }^{1,2^{*}}$, Mohamed Amine Azami ${ }^{1,2}$, Rajae Daoudi ${ }^{2,3}$ and Nadia Cherradi ${ }^{1,2}$
}

\begin{abstract}
Background: In lacrimal gland, lymphomas and inflammatory lesions predominate. Primary epithelial tumours represent less than 30\% of lacrimal gland lesions. Myoepithelial carcinoma of lacrimal gland is rare. To the best of our knowledge, only nine cases have been reported in the literature. This lesion presents diagnostic difficulties: non-specific clinical and radiological findings and histological polymorphism. This is well illustrated by the diagnostic pathology errors described in the literature.

We report a new case of lacrimal myoepithelial carcinoma with a review of others published cases to try to assess clinico-pathological features and outcome whenever possible of this rare tumour.

Case presentation: An 80-year-old Arabian female presented with a 2-month history of swelling over the right eyebrow, pain, proptosis of the right eye and diplopia. Computed tomography demonstrated an ill-defined, homogeneous, contrast-enhancing mass attached to the medial rectus. A biopsy was performed. Microscopic examination showed malignant spindle cells tumour, most consistently to sarcoma or sarcomatoid carcinoma. Immunohistochemical study was not possible because neoplastic material has been exhausted. Subsequently, total exenteration of the right orbit was performed. Immunohistochemical study revealed diffuse positive staining for pancytokeratin AE1/AE3, epithelial membrane antigen (EMA) and smooth muscle actin (SMA) and focal positivity for S100 protein. The lesion was immunonegative for desmin, h-cladesmon, CD34, Melan-A and HMB-45. The tumour was extending to the surgical margins. The patient was lost to follow-up until she developed local tumour progression 3 months after removal. The patient was again lost to follow-up and therefore did not receive any other treatment in our hospital.

Conclusion: We present this rare tumour with an unusual location. The use of a complete immunohistochemical panel with epithelial and myoepithelial markers positivity helped us for classification of this poorly differentiated tumour.
\end{abstract}

Keywords: Myoepithelial carcinoma, Lacrimal gland, Immunohistochemistry

\section{Background}

Lacrimal gland lesions represent $9 \%$ of all space-occupying orbital lesions [1]. Lymphomas and inflammatory lesions predominate $[2,3]$. Primary epithelial tumours represent less than $30 \%$ of lacrimal gland lesions [2, 4]. Pleomorphic adenoma is the most frequent, accounting for

\footnotetext{
* Correspondence: ysf.mahdi@gmail.com

'Department of Pathology, Specialties Hospital, Ibn Sina University Hospital, Rabat, Morocco

${ }^{2}$ Faculty of Medicine and Pharmacy, Mohammed V University of Rabat, Villa 670, Sala Al Jadida, Salé, Morocco

Full list of author information is available at the end of the article
}

approximately $50 \%$ of epithelial tumours [2, 4-6]. Adenoid cystic carcinoma is the most frequent malignant tumour [4-6].

Myoepithelial carcinoma of lacrimal gland is rare. To the best of our knowledge, only nine cases have been reported in the literature [6-14]. This lesion presents diagnostic difficulties. The clinical and radiological findings are not specific. The tumour is characterized by histological polymorphism. This is well illustrated by the diagnostic pathology errors described in the literature.

We report a new case of lacrimal myoepithelial carcinoma with a review of others published cases to try to 
assess clinico-pathological features and outcome whenever possible of this rare tumour.

\section{Case presentation}

An 80-year-old Arabian female presented to our hospital with a 2-month history of swelling over the right eyebrow, pain, proptosis of the right eye and diplopia (Fig. 1). Physical examination revealed a $2 \mathrm{~cm}$ ill-defined painful mass over the right eyebrow. The patient complains of double vision looking to the left. Computed tomography (CT) of the right orbit demonstrated an ill-defined, homogeneous, contrast-enhancing mass attached to the medial rectus. As a space-occupying orbital lesion, a lymphoma or a sarcoma was suspected. As a result, a biopsy was performed. On microscopic examination, the tumour was composed of interlacing bundles of spindle cells with anisokaryosis and hyperchromatic nuclei (Fig. 2). Some mitotic figures were observed. Immunohistochemical study was not possible because neoplastic material has been exhausted. The conclusion was malignant spindle cells tumour, most consistently to sarcoma or sarcomatoid carcinoma. No lymph node or distant metastases were found. Subsequently, total exenteration of the right orbit was performed under general anaesthesia. Dilute adrenaline was injected to lessen bleeding generally abundant in this type of excision. Periosteum was incised right around the orbital rim and separated from the bone passing back towards the orbital apex. The eyeball, eyelids, appendages of the eye and periosteum were removed. Surgical specimen was addressed for pathological examination. At gross examination, the tumour appeared ill-defined, whitish and firm. It measured $4 / 2.5 / 1.5 \mathrm{~cm}$. It was attached to the sclera without infiltration into eyeball. It infiltrated the upper eyelid (Fig. 3). Microscopic examination revealed spindle cells forming disorganized fascicles. They have an irregular nucleus with vesicular chromatin and an eosinophilic cytoplasm. The mitotic index was 18 per 10 high-power fields. Adipose tissue and striated muscle infiltration was observed (Fig. 4). Immunohistochemical panel used for initial work up of this high grade spindle cell neoplasm was desmin, smooth muscle actin (SMA), pancytokeratin AE1/ AE3, epithelial membrane antigen (EMA), S100 protein and CD34. This panel served to rule out first leiomyosarcoma, rhabdomyosarcoma, sarcomatoid carcinoma and spindle cell melanoma. It revealed diffuse positive staining for pancytokeratin AE1/AE3, EMA and SMA and focal positivity for $\mathrm{S} 100$ protein (Fig. 5). The lesion was immunonegative for desmin and CD34 (Fig. 6). As pancytokeratin AE1/AE3, EMA, SMA and S100 protein staining was positive, we completed by second panel. It showed h-cladesmon, Melan-A and HMB-45 negative staining. These pathological and immunohistochemical findings suggested the diagnoses of myoepithelioma, epithelial myoepithelial carcinoma and myoepithelial carcinoma. Myoepithelioma was excluded because the tumour borders were infiltrative. Epithelial myoepithelial carcinoma is by definition composed of a biphasic arrangement of inner luminal ductal cells and outer myoepitheliaI cells. However, the tumour did not show bi-layered duct-like structures. The most appropriate diagnosis was myoepithelial carcinoma. The tumour was extending to upper and posterior surgical margins. Radiotherapy was then indicated. The patient was lost to follow-up until she developed local tumour

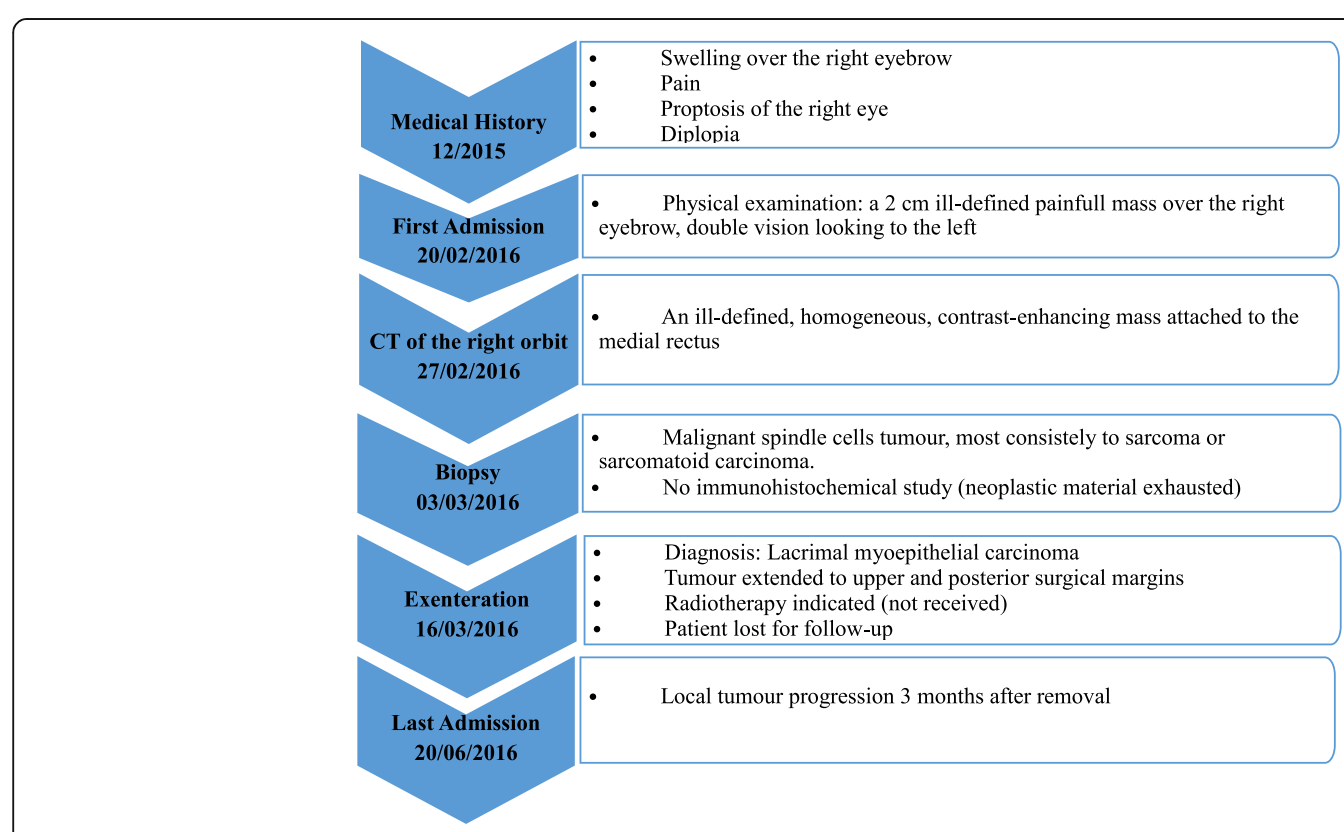

Fig. 1 Case report timeline 


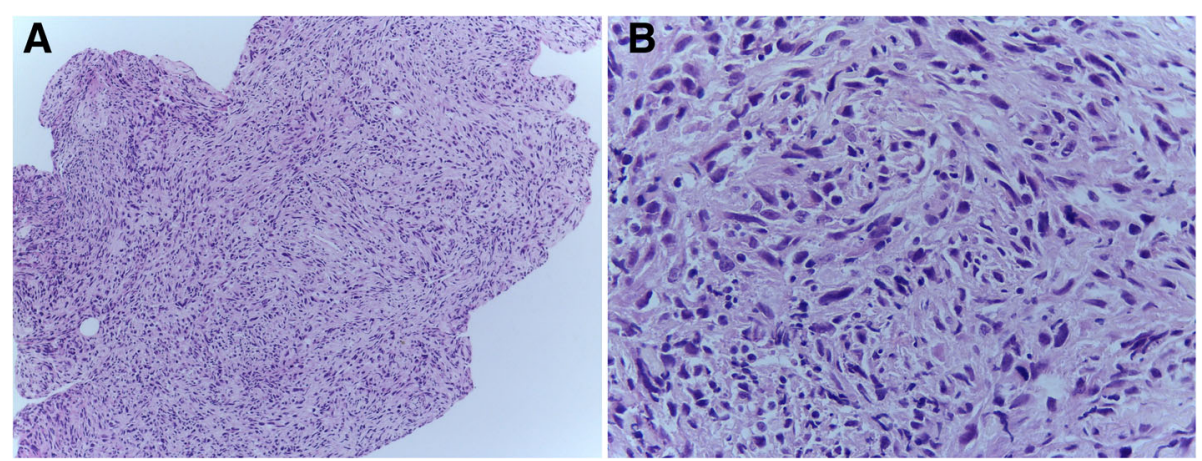

Fig. 2 Histological aspect of the lesion in biopsy: a The tumour is composed of interlacing bundles of spindle cells (H\&E $\times 100)$. $\mathbf{b}$ The neoplastic cells show anisokaryosis and hyperchromatic nuclei (H\&E $\times 400)$

progression 3 months after removal. The patient was again lost to follow-up and therefore did not receive any other treatment in our hospital.

\section{Discussion}

In our case there was no obvious attachment to lacrimal tissue. But, according to Shields JA et al. $[15,16]$, the lacrimal gland is the only structure where epithelial cells are encountered in the orbit. Therefore, this primary myoepithelial carcinoma was considered to have its origin in the lacrimal gland.

The clinical and radiological findings of lacrimal myoepithelial carcinomas were described with details in only six cases in the literature [8-10, 12-14] (Table 1). These features were not specific. The lesion size varied from 1.6 to $4 \mathrm{~cm}$.

The tumour occurred de novo $[6,8,12]$ or on a pre-existing pleomorphic adenoma or adenoid cystic carcinoma $[9,10,13,14]$. De novo lacrimal myoepithelial carcinoma would have a poorer prognosis when compared to lacrimal myoepithelial carcinoma arising from pleomorphic adenoma or adenoid cystic carcinoma.

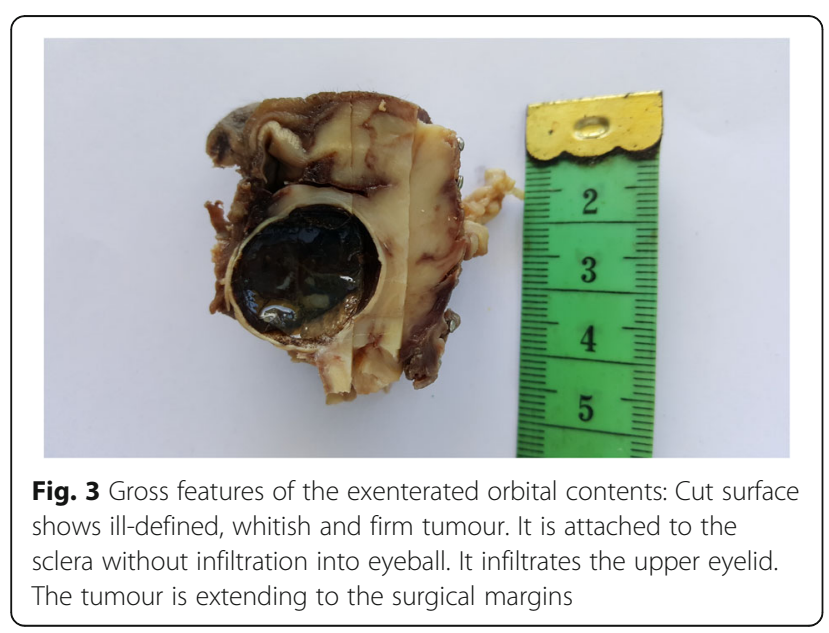

Diagnoses discussed before pathological examination were not specified neoplasms, pseudo-tumours, hemangioma, lymphoma, sarcoma or metastatic process.

For the histological classification of epithelial lacrimal gland tumours, the World Health Organization (WHO) classification of salivary gland tumours is currently applied [17]. Indeed, the lacrimal and salivary glands present histological and pathological similarities. In addition, the WHO classification of these rare lacrimal gland tumours has not changed since 1980 [18].

At the salivary glands, WHO defines myoepithelial carcinoma as a malignancy entirely composed of neoplastic myoepithelial cells with an infiltrative growth [19]. The neoplastic cells can take on various morphological appearances: spindle, epithelioid, plasmacytoid or clear. In our case, the tumour was very cellular composed of spindle-shaped cells and resembled sarcoma. The tumour cells are most commonly arranged in solid, trabecular or reticular patterns [19]. Central necrosis and pseudocyst formation may occur [19]. Infiltrative and destructive growth is the major histological feature associated with malignant behavior [19].

Immunohistochemistry is required for the diagnosis. It demonstrates the myoepithelial nature of neoplastic cells. The diagnosis requires reactivity for cytokeratin and at least one of myoepithelial markers: SMA, glial fibrillary acidic protein (GFAP), calponin, S-100 protein, p63 and CK 5/6 [6-10, 12-14, 19]. No genetics studies were performed in the reported cases.

Due to histological polymorphism and rarity of the lesion in the lacrimal gland, myoepithelial carcinoma poses significant challenges in differential diagnosis. This is well illustrated by the diagnostic errors described in the literature (Table 2).

Weiss et al., in a retrospective multicenter cohort study of 118 cases of epithelial neoplasia found one case of myoepithelial carcinoma [6]. It was initially diagnosed as malignant epithelial neoplasm, most consistent with adenoid cystic carcinoma. It was composed of nests of 

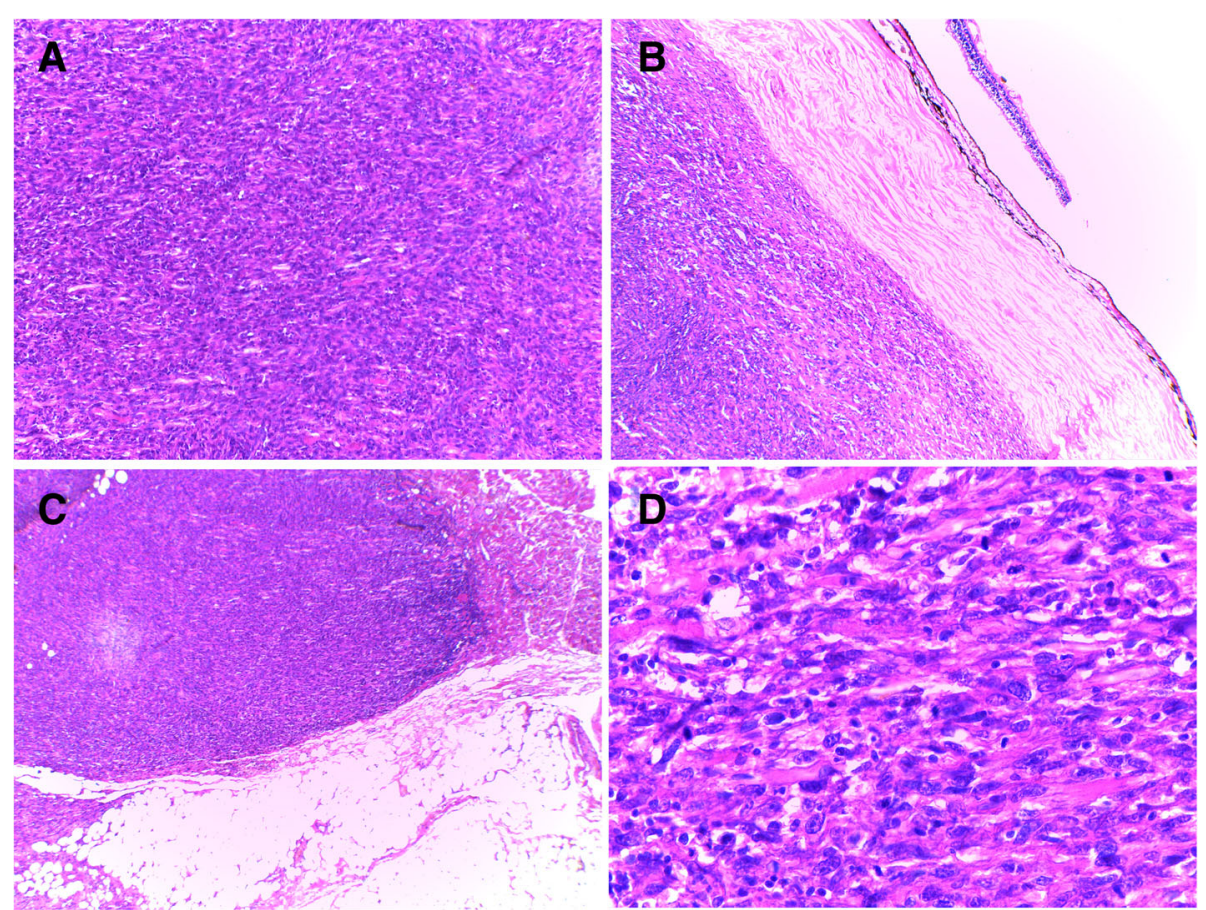

Fig. 4 Histological aspect of the tumour after orbital exenteration: a Neoplastic spindle cells are arranged in disorganized fascicules (H\&E $\times 100$ ). b The tumour is attached to the sclera without infiltration (H\&E $\times 40)$. c Infiltration into adipose tissue and striated muscle is observed (H\&E $\times 40$ ). d High-power view shows the obvious cytologic atypia and several mitoses of the neoplastic cells (H\&E $\times 400)$

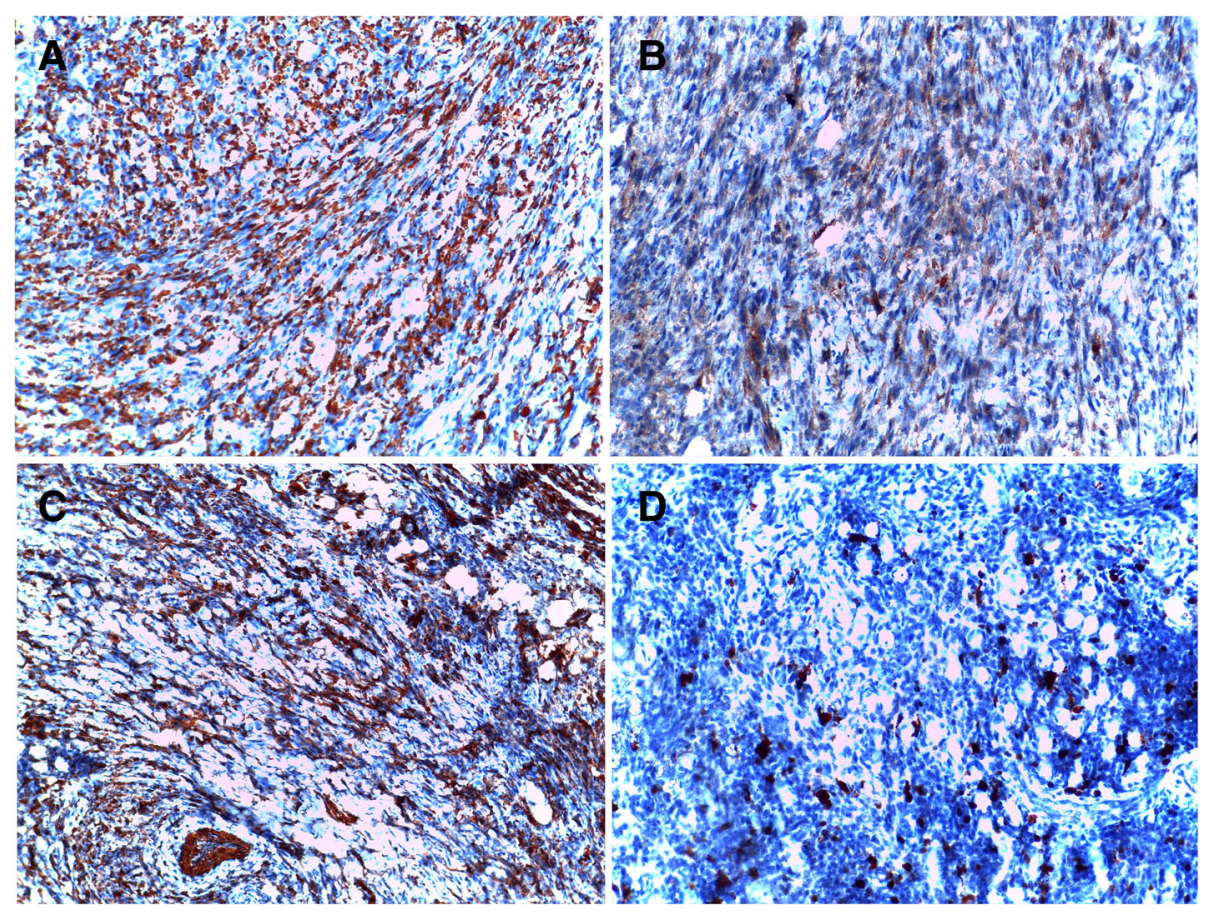

Fig. 5 Immunohistochemical profile of the tumour after orbital exenteration: The tumor cells express pancytokeratin AE1/AE3 a, EMA b, SMA (c) and express focally $\mathbf{S 1 0 0}$ protein (d) 


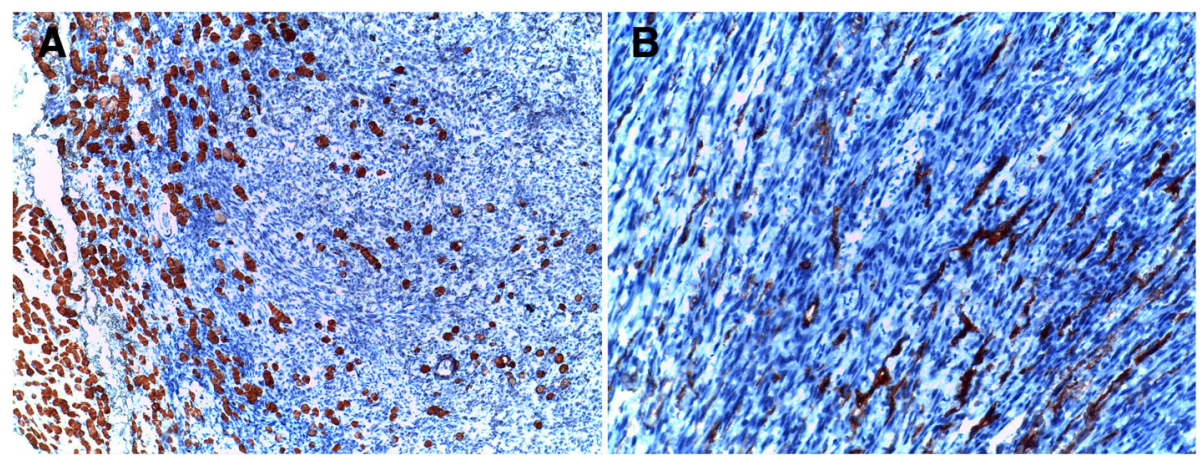

Fig. 6 Immunohistochemical profile of the tumour after orbital exenteration: The tumor cells are negative for desmin (a) (infiltrated skeletal muscle fibers are staining with desmin) and CD34 (b) (vessel endothelial cells are staining with CD34)

epithelioid and clear cells with nuclear atypia. The immunohistochemical study showed positive staining for keratin, S-100 protein and actin.

In the case reported by Argyris et al. [10], no immunohistochemical stains were initially performed and the tumour was diagnosed as carcinoma ex-pleomorphic adenoma. After tumour recurrence, review of the histologic sections was done. The neoplasm was composed of an admixture of adenoid cystic carcinoma and poorly differentiated component expressing pancytokeratin AE1-AE3, CK 5/6, EMA, p16, SMA, S-100 protein, calponin and p63.

In another case, the tumour was composed exclusively of spindle-shaped cells [12]. It infiltrated the right lateral rectus and lacrimal gland. It had SMA positive staining at immunohistochemistry. It was diagnosed as leiomyosarcoma and surgical excision was indicated. The lesion showed spindle cells proliferation with a positive immunostaining for SMA and P63 and bi-layered duct-like structures. The diagnosis was epithelial-myoepithelial carcinoma, which is a low-grade tumor. Surveillance was recommended. Locoregional recurrence was observed 3 months after removal. The tumour was reclassified as myoepithelial carcinoma after histological review. The bilayered structures were entrapped non-neoplastic acinar structures.

In addition, Rabade et al. reported the case of tumour composed exclusively of clear cells [13]. It infiltrated surrounding bone trabeculae and striated muscle. These findings could make the diagnosis of clear cell carcinoma-not otherwise specified (NOS). Positive

Table 1 Clinical and radiological findings in cases of lacrimal myoepithelial carcinomas described in the literature

\begin{tabular}{|c|c|c|c|}
\hline Cases & Age-sex & Clinical presentation & Radiologic findings \\
\hline Weis et al. [6] & Not reported & Not reported & Not reported \\
\hline Herrera et al. [7] & Not reported & Not reported & Not reported \\
\hline lida et al. [8] & 77 year-old, man & Proptosis & Not reported \\
\hline $\begin{array}{l}\text { Wiwatwongwana } \\
\text { et al. [9] }\end{array}$ & 84 year-old, man & $\begin{array}{l}\text { Proptosis, Severe decreasing } \\
\text { of vision Ocular pain Eyeball } \\
\text { displacement }\end{array}$ & $\begin{array}{l}\mathrm{CT} \text { : a } 3.2 / 2.6 / 2.2 \mathrm{~cm} \text { well-circumscribed, calcified lacrimal } \\
\text { gland mass extending to the apex, displacing the globe } \\
\text { with irregularity in the adjacent bony orbital wall }\end{array}$ \\
\hline Argyris et al. [10] & 39 year-old, woman & Proptosis & $\begin{array}{l}\mathrm{CT} \text { and MRI: a } 3 / 2.2 / 2 \mathrm{~cm} \text { extraconal mass effacing the } \\
\text { lacrimal grand and displacing the left lateral rectus, } \\
\text { optic nerve and globe }\end{array}$ \\
\hline Von Holstein et al. [11] & Not reported & Not reported & Not reported \\
\hline Moret et al. [12] & 88 year-old, man & $\begin{array}{l}\text { Proptosis Decreasing of vision } \\
\text { Lateral rectus muscle paralysis }\end{array}$ & $\begin{array}{l}\text { MRI: a } 3.5 / 2.5 / 1.7 \mathrm{~cm} \text { intra- and extra-conal mass, extending } \\
\text { to the lacrimal gland and the lateral rectus muscle }\end{array}$ \\
\hline Rabade et al. [13] & 27-year-old, man & $\begin{array}{l}\text { Proptosis Decreasing of vision } \\
\text { Swelling over the eyebrow }\end{array}$ & $\begin{array}{l}\text { MRI: a well-defined, lobulated, contrast-enhancing mass in the } \\
\text { superolateral compartment of the orbit with erosion of the } \\
\text { lateral wall and roof and extending into the right frontal region }\end{array}$ \\
\hline $\begin{array}{l}\text { Larbcharoensub } \\
\text { et al. [14] }\end{array}$ & 68-year-old, woman & $\begin{array}{l}\text { Proptosis Mass in the superior } \\
\text { temporal part of the orbit Visual } \\
\text { acuity of no light perception }\end{array}$ & $\begin{array}{l}\text { MRI: a } 3.8 / 3.7 / 3.3 \mathrm{~cm} \text { well-defined, lobulated, vivid inhomogeneous } \\
\text { enhancing isosignal T1W/slightly hypersignal T2W mass. It located } \\
\text { at retrobulbar portion involving extraconal-conal-intraconal spaces } \\
\text { of the orbit and invading of the lateral bony wall }\end{array}$ \\
\hline $\begin{array}{l}\text { Case presented } \\
\text { (Mahdi et al.) }\end{array}$ & 80 year-old, woman & $\begin{array}{l}\text { Proptosis Pain Swelling over } \\
\text { the eyebrow Diplopia }\end{array}$ & $\begin{array}{l}\mathrm{CT} \text { : an ill-defined, homogeneous, contrast-enhancing mass } \\
\text { attached to the medial rectus }\end{array}$ \\
\hline
\end{tabular}


Table 2 Diagnostic pathology errors in cases of lacrimal myoepithelial carcinomas described in the literature

\begin{tabular}{ll}
\hline Cases & Diagnostic pathology errors \\
\hline Weis et al. & Adenoid cystic carcinoma \\
Argyris et al. & Carcinoma ex-pleomorphic adenoma \\
Moret et al. & Biopsy: Leiomyosarcoma \\
& Exenteration: Epithelial-myoepithelial \\
& carcinoma \\
Case presented (Mahdi et al.) & Sarcoma/Sarcomatoid carcinoma \\
\hline
\end{tabular}

immunostaining with calponin identified the myoepithelial differentiation.

The sarcoma-like feature in the orbit can also evoke sarcomatoid carcinoma. It is positive for pancytokeratin AE1/AE3 and P63 but lakes S100 protein expression.

Surgical resection was the principal treatment in the reported cases. It consisted to wide local excision or exenteration of the orbit. No distant metastasis were found. In three cases, local or locoregional recurrences were diagnosed between 3 and 24 months $[10,12,13]$. Tumour cells were found in the resection margins $[10,12]$. One of these three patients received palliative radiotherapy and died 8 months after diagnosis [12]. Another patient died within months of diagnosis without definitive treatment [6]. These two patients died from de novo myoepithelial carcinoma $[6,12]$. One patient with myoepithelial carcinoma arising in pleomorphic adenoma presented three uneventful years without any adjuvant therapy [14]. Additional cases are needed to better characterize primary lacrimal myoepithelial carcinoma.

\section{Conclusions}

We present this rare tumour with an unusual location. Given recurrence and death reported in patients with lacrimal myoepithelial carcinoma, correct diagnosis is imperative. The use of a complete immunohistochemical panel with epithelial and myoepithelial markers positivity helped us for classification of this poorly differentiated tumour.

\section{Abbreviations}

CT: Computed tomography; EMA: Epithelial membrane antigen; GFAP: Glial fibrillary acidic protein; MRI: Magnetic resonance imaging; NOS: Not otherwise specified; SMA: Smooth muscle actin; WHO: World Health Organization

\section{Acknowledgements}

Acknowledgements to Adiba Bakkour for language corrections.

\section{Authors' contributions}

YM and NC performed histological analysis. YM performed the literature search, drafted the manuscript and made the figures. MAA and RD reviewed clinical and surgical data. RD and NC critically reviewed the manuscript. All authors read and approved the final manuscript.
Ethics approval and consent to participate

Not applicable.

\section{Consent for publication}

Written informed consent was obtained from the patient for publication of this case report and accompanying images. A copy of the written consent is available for review by the Editor-in-Chief of this journal.

\section{Competing interests}

The authors declare that they have no competing interests.

\section{Publisher's Note}

Springer Nature remains neutral with regard to jurisdictional claims in published maps and institutional affiliations.

\section{Author details}

${ }^{1}$ Department of Pathology, Specialties Hospital, Ibn Sina University Hospital, Rabat, Morocco. ${ }^{2}$ Faculty of Medicine and Pharmacy, Mohammed V University of Rabat, Villa 670, Sala Al Jadida, Salé, Morocco. ${ }^{3}$ Department of Ophtalmology, Specialties Hospital, Ibn Sina University Hospital, Rabat, Morocco.

Received: 19 March 2018 Accepted: 26 July 2018

Published online: 02 August 2018

\section{References}

1. Shields JA, Shields CL, Scartozzi R. Survey of 1264 patients with orbital tumors and simulating lesions: the 2002 Montgomery lecture, part 1. Ophthalmology. 2004;111(5):997-1008.

2. Shields CL, Shields JA, Eagle RC, Rathmell JP. Clinicopathologic review of 142 cases of lacrimal gland lesions. Ophthalmology. 1989;96(4):431-5.

3. Kennedy RE. An evaluation of 820 orbital cases. Trans Am Ophthalmol Soc. 1984:82:134 57.

4. Johansen S, Heegaard S, Bogeskov L, Prause JU. Orbital space-occupying lesions in Denmark 1974-1997. Acta Ophthalmol Scand. 2000;78(5):547-52.

5. Ni C, Kuo P-K, Dryja T. Histopathological classification of 272 primary epithelial tumors of the lacrimal gland. Chin Med J. 1992;105(6):481-5.

6. Weis E, Rootman J, Joly TJ, Berean KW, Al-Katan HM, Pasternak S, Bonavolontà G, Strianese D, Saeed P, Feldman KA, Vangveeravong $S$, Lapointe JS, White VA. Epithelial lacrimal gland tumors: pathologic classification and current understanding. Arch Ophthalmol. 2009;127(8): 1016-28.

7. Herrera GA. Light microscopic, ultrastructural and immunocytochemical spectrum of malignant lacrimal and salivary gland tumors, including malignant mixed tumors. Pathobiology. 1990;58(6):312-22.

8. lida K, Shikishima K, Okido M, Sato S, Masuda Y. A case of malignant myoepithelioma in the lacrimal gland. Nippon Ganka Gakkai Zasshi. 2001; 105(1):42-6.

9. Wiwatwongwana D, Berean KW, Dolman PJ, Rootman J, White VA. Unusual carcinomas of the lacrimal gland: epithelial-myoepithelial carcinoma and myoepithelial carcinoma. Arch Ophthalmol. 2009;127(8):1054-6.

10. Argyris PP, Pambuccian SE, Cayci Z, Singh C, Tosios KI, Koutlas IG. Lacrimal gland adenoid cystic carcinoma with high-grade transformation to myoepithelial carcinoma: report of a case and review of literature. Head Neck Pathol. 2013;7(1):85-92

11. von Holstein SL, Therkildsen MH, Prause JU, Stenman G, Siersma VD, Heegaard S. Lacrimal gland lesions in Denmark between 1974 and 2007. Acta Ophthalmol. 2013;91(4):349-54.

12. Moret A, Tabareau-Delalande F, Joly A, de Muret A, Goga D, Laure B. Myoepithelial carcinoma of the lacrimal gland. Rev Stomatol Chir Maxillofac Chir Orale. 2014;115(3):172-7.

13. Rabade NR, Goel NA. Clear cell myoepithelial carcinoma ex pleomorphic adenoma. Indian J Pathol Microbiol. 2014;57(3):456-9.

14. Larbcharoensub N, Pangpunyakulchai D, Aroonroch R, Tuntiyatorn L, Mahaisavariya P. Lacrimal myoepithelial carcinoma ex recurrent pleomorphic adenoma: a clinicopathological report and review of the literature. Mol Clin Oncol. 2018;8(1):209-13.

15. Shields JA, Shields CL, Eagle RC Jr, Adkins J, De Potter P. Adenoid cystic carcinoma developing in the nasal orbit. Am J Ophthalmol. 1997;123:398-9.

16. Shields JA, Shields CL. Lacrimal gland primary epithelial tumors. In: Shields $J A$, Shields CL, editors. Eyelid, orbital and conjunctival tumors, An atlas and 
textbook. 2nd ed. Philadelphia, PA: Lippincott, Williams and Wilkins; 2008. p. $700-25$.

17. AK El-N, JKC C, Grandis JR, Takata T, Slootweg PJ, editors. World Health Organization Classification of Head and Neck Tumours. 4th ed. Lyon: IARC; 2017.

18. Zimmerman L, Sobin L. Histological typing of tumours of the eye and its adnexa, vol. 24. Geneva: World Health Organization; 1980.

19. Bell D, Di Palma S, Katabi N, Schwartz MR, Seethala R, Skalova A. Myoepithelial Carcinoma (Salivary Glands). In: AK El-N, JKC C, Grandis JR, Takata T, Slootweg PJ, editors. World Health Organization Classification of Head and Neck Tumours. 4th ed. Lyon: IARC; 2017. p. 174-5.

Ready to submit your research? Choose BMC and benefit from:

- fast, convenient online submission

- thorough peer review by experienced researchers in your field

- rapid publication on acceptance

- support for research data, including large and complex data types

- gold Open Access which fosters wider collaboration and increased citations

- maximum visibility for your research: over $100 \mathrm{M}$ website views per year

At $\mathrm{BMC}$, research is always in progress.

Learn more biomedcentral.com/submissions 